\title{
Retraction Note to: Structured Decision-Making Identifies Effective Strategies and Potential Barriers for Ecosystem-Based Management of a Range-Extending Species in a Global Marine Hotspot
}

Lucy M. Robinson, ${ }^{1,2,7 *}$ Martin P. Marzloff, ${ }^{1,6}$ Ingridvan Putten, ${ }^{3,4}$ Gretta Pecl, ${ }^{3,4}$ Sarah Jennings, ${ }^{4,8}$ Sam Nicol, ${ }^{5}$ Alistair J. Hobday, ${ }^{3,4}$ Sean Tracey, ${ }^{1,4}$ Klaas Hartmann, ${ }^{1}$ Marcus Haward, ${ }^{4}$ and Stewart Frusher ${ }^{4}$

${ }^{1}$ Institute for Marine and Antarctic Studies, Hobart, TAS 7001, Australia; ${ }^{2}$ Oceans Institute and Oceans Graduate School, The University of Western Australia, Perth 6009, Australia; ${ }^{3}$ CSIRO Oceans and Atmosphere, Hobart, TAS 7000, Australia; ${ }^{4}$ Centre for

Marine Socioecology, University of Tasmania, Hobart, TAS 7000, Australia; ${ }^{5}$ CSIRO Land and Water, Dutton Park, QLD 4102, Australia; ${ }^{6}$ IFREMER Centre de Bretagne, DYNECO Benthic Ecology Laboratory (LEBCO), CS 10070, 29280 Plouzané, France; ${ }^{7}$ CSIRO Oceans and Atmosphere, Crawley, WA 6009, Australia; ${ }^{8}$ Tasmanian School of Business and Economics, University of Tasmania, Hobart, TAS 7000, Australia

Retraction Note to:

ECOSYSTEMS (2019) 22: 1573-1591 HTTPS://DOI.ORG/10.1007/s10021-01900358-w

The authors are retracting this article [1] because of confidentiality reasons. The article has been removed to protect the privacy of an individual. All authors agree to this retraction.
1. Robinson LM, Marzloff MP, van Putten I, et al. 2019. Structured decision-making identifies effective strategies and potential barriers for ecosystem-based management of a range-extending species in a global marine hotspot. Ecosystems 22:1573-91. https://doi.org/10.100 7/s10021-019-00358-W

Published online 2 September 2020

The original article can be found online at https://doi.org/10.1007/s100 21-019-00358-w.

*Corresponding author; e-mail: lucy.m.e.robinson@gmail.com 